\title{
Complete nucleotide sequence of the mitochondrial genome of a salamander, Mertensiella luschani
}

\author{
Rafael Zardoya ${ }^{\mathrm{a}, *}$, Edward Malaga-Trillo ${ }^{\mathrm{b}}$, Michael Veith ${ }^{\mathrm{c}}$, Axel Meyer ${ }^{\mathrm{b}}$ \\ ${ }^{a}$ Museo Nacional de Ciencias Naturales, CSIC, José Gutiérrez Abascal, 2, 28006 Madrid, Spain \\ ${ }^{\mathrm{b}}$ Department of Biology, University of Konstanz, D-78457 Konstanz, Germany \\ ${ }^{\mathrm{c}}$ Institut für Zoologie, Abt. Populationsbiologie, Universität Mainz, Saarstraße 21, 55099 Mainz, Germany
}

Received 18 July 2002; received in revised form 29 November 2002; accepted 28 April 2003

\begin{abstract}
The complete nucleotide sequence $(16,650 \mathrm{bp})$ of the mitochondrial genome of the salamander Mertensiella luschani (Caudata, Amphibia) was determined. This molecule conforms to the consensus vertebrate mitochondrial gene order. However, it is characterized by a long non-coding intervening sequence with two 124-bp repeats between the $\mathrm{tRNA}^{\mathrm{Thr}}$ and $\mathrm{tRNA}{ }^{\text {Pro }}$ genes. The new sequence data were used to reconstruct a phylogeny of jawed vertebrates. Phylogenetic analyses of all mitochondrial protein-coding genes at the amino acid level recovered a robust vertebrate tree in which lungfishes are the closest living relatives of tetrapods, salamanders and frogs are grouped together to the exclusion of caecilians (the Batrachia hypothesis) in a monophyletic amphibian clade, turtles show diapsid affinities and are placed as sister group of crocodiles+birds, and the marsupials are grouped together with monotremes and basal to placental mammals. The deduced phylogeny was used to characterize the molecular evolution of vertebrate mitochondrial proteins. Amino acid frequencies were analyzed across the main lineages of jawed vertebrates, and leucine and cysteine were found to be the most and least abundant amino acids in mitochondrial proteins, respectively. Patterns of amino acid replacements were conserved among vertebrates. Overall, cartilaginous fishes showed the least variation in amino acid frequencies and replacements. Constancy of rates of evolution among the main lineages of jawed vertebrates was rejected.
\end{abstract}

(C) 2003 Elsevier B.V. All rights reserved.

\section{Introduction}

Salamanders, the tailed amphibians (order Caudata), may represent a living paradigm of the tempo and mode in which the adaptations that are required to live on land were acquired in the evolution of vertebrates. Many of the 400 or so living salamander species (Frost, 1985) display peculiar feeding, breathing, urogenital, and reproductive apparati, which can be interpreted as alternative or sequential morphological adaptations to terrestrial life that were evolved when sarcopterygian ancestors of amphibians colonized land in the Devonian (360 MYA). Moreover, salamanders are also characterized by a wide variety of gametogenetic, mating, developmental, and parental care

\footnotetext{
* Corresponding author. Tel.: +34-91-4111328x1129; fax: +34-915645078 .

E-mail address: rafaz@mncn.csic.es (R. Zardoya).
}

strategies (Duellman and Trueb, 1994), which can be perceived as an adaptation to permit reproduction on terrestrial conditions.

To trace and better understand the sequence of evolutionary events that produced the diversity in life modes exhibited by salamanders, it is mandatory first to infer the phylogenetic relationships of the group with other living amphibians (i.e. frogs and caecilians) and with other vertebrates (Titus and Larson, 1995). Therefore, we determined the complete sequence of the mitochondrial genome of an old world salamander, Mertensiella luschani. The usefulness of these new mitochondrial sequence data in resolving controversies on amphibian phylogenetic relationships was addressed elsewhere (Zardoya and Meyer, 2001). Here, we present a formal description of the molecular and structural features of the salamander mitochondrial genome and compared it with the complete mitochondrial genomes of other relevant jawed vertebrates. 


\section{Materials and methods}

\subsection{Mitochondrial DNA extraction}

Mitochondrial DNA (mtDNA) was purified from eggs and liver of six specimens of the salamander species $M$. luschani, as previously described (Zardoya et al., 1995). After homogenization, mitochondria were separated from intact nuclei and cellular debris by a low-speed centrifugation. Mitochondrial DNA was extracted from isolated mitochondria by a standard alkaline lysis procedure, and cleaved with EcoRI and HindIII restriction enzymes. Two EcoRI fragments of 1.3 (comprising the complete control region) and 0.7 (partial ND1) kb, and four HindIII fragments of 2.2 (including the $3^{\prime}$ end of $\mathrm{COI}$ and $5^{\prime}$ end of COII), $0.9\left(5^{\prime}\right.$ end of COI), 0.9 (partial ND2), and 0.6 ( $5^{\prime}$ end of ND1 to tRNA-Met) $\mathrm{kb}$ were cloned into pUC18.

\subsection{PCR amplification, cloning, and sequencing}

The remaining portion of the mitochondrial molecule was amplified by PCR using the mtDNA extract as DNA

Table 1

PCR and sequencing primers utilized in the analysis of the salamander mt genome

\begin{tabular}{|c|c|c|}
\hline Primer & Sequence $\left(5^{\prime} \rightarrow 3^{\prime}\right)$ & Approximate product length $(\mathrm{bp})$ \\
\hline \multicolumn{3}{|l|}{$\overline{P C R}$} \\
\hline Sal $12 \mathrm{~S} \mathrm{~F}$ & TGT GAA AAT GCC CTT TAT TAC CA & \multirow[t]{2}{*}{400} \\
\hline Sal $12 \mathrm{~S} R$ & GTG GCT CGT AGT ACT CTG GCG GA & \\
\hline${\mathrm{L} 1091^{\mathrm{a}}}$ & AAA AAG CTT CAA ACT GGG ATT AGA TAC CCC ACT AT & \multirow[t]{2}{*}{400} \\
\hline $\mathrm{H} 1478^{\mathrm{a}}$ & TGA CTG CAG AGG GTG ACG GGC GGT GTG T & \\
\hline Sal 12S F1 & GAA TGA TTC TAT GAA ATA ATT TC & \multirow[t]{2}{*}{400} \\
\hline Sal 16S R & TTT GAC TTA CTA GAC CAT TAT GC & \\
\hline $16 \mathrm{~S}-1 \mathrm{~L}^{\mathrm{b}}$ & AGT ACC GCA AGG GAA ARC TGA AA & \multirow[t]{2}{*}{800} \\
\hline $16 \mathrm{~S}-2 \mathrm{H}^{\mathrm{b}}$ & GAT TRY GCT ACC TTY GCA CGG TCA & \\
\hline $16 \operatorname{Sar}^{\mathrm{c}}$ & CGC CTG TTT ATC AAA AAC AT & \multirow[t]{2}{*}{500} \\
\hline $16 \mathrm{Sbr}^{\mathrm{c}}$ & CCG GTC TGA ACT CAG ATC ACG T & \\
\hline Sal 16S F & ATG GTG TAG CCG CTA TTA AAG GT & \multirow[t]{2}{*}{550} \\
\hline Sal ND1 R & AGA AGG GTA GAG GTA GTG GAA TT & \\
\hline Sal AT8 F & ATC ACA GCT TCA TAC CAA TTG TT & \multirow[t]{2}{*}{1200} \\
\hline Sal AT8 R & CAG GAG TAG TGT GGT GTC CTT GA & \\
\hline LATI COIII $\mathrm{F}^{\mathrm{b}}$ & ATA TAT CAA TGA TGA CGA GA & \multirow[t]{2}{*}{600} \\
\hline LATI COIII R $1^{\mathrm{b}}$ & ACA TCA ACG AAA TGT CAG TAC CA & \\
\hline Sal COIII F & GAA GCC CCA TTC ACA ATC GCA GA & \multirow[t]{2}{*}{700} \\
\hline Sal ND4 R & TGA GCC GAA ATC ANN GGT CTT & \\
\hline Sal ND3 F & GAA TGA GTC CAA GGA GGC CTT GAA T & \multirow[t]{2}{*}{1100} \\
\hline Sal ND4R1 & ATT CCG TAG CCT CCG AGT TTT & \\
\hline $\mathrm{ND} 4^{\mathrm{d}}$ & CAC CTA TGA CTA CCA AAA GCT CAT GTA GAA GC & \multirow[t]{2}{*}{900} \\
\hline Leu $^{\text {d }}$ & CAT TAC TTT TAC TTG GAT TTG CAC CA & \\
\hline LATI Leu $\mathrm{F}^{\mathrm{b}}$ & CTA AAG GAT AAT AGC TCA TCC ATT & \multirow{2}{*}{500} \\
\hline Sal ND5 R & CAT CAC CCA ATA AGT AAG AAG GA & \\
\hline LATI ND5 $\mathrm{F}^{\mathrm{b}}$ & CAR YTA TTY ATC GGN TGR GAR GG & \multirow[t]{2}{*}{650} \\
\hline LATI ND5 R1 ${ }^{\mathrm{b}}$ & CCY ATY TTT CKG ATR TCY TGY TC & \\
\hline Sal ND5 F & TGT TCT GGG TCA ATT ATT CAC AA & \multirow[t]{2}{*}{1400} \\
\hline Sal Glu R & TTA ATA ATT TTT AGT AGT GGG TGA & \\
\hline$M V Z-15 \mathrm{~F}^{\mathrm{e}}$ & GAA CTA ATG GCC CAC ACW WTA CGN AA & \multirow[t]{2}{*}{400} \\
\hline $\mathrm{H} 1514 \mathrm{~g}^{\mathrm{a}}$ & AAA CTG GAG CCC CTC AGA ATG ATA TTT GTC CTC A & \\
\hline Sal Cytb F1 & TAT AAA GAG ACA TGA AAT AT & \multirow[t]{2}{*}{1200} \\
\hline Sal Pro $\mathrm{R}$ & TTT AGA AGT CTA GAA TTT TGG CCT & \\
\hline \multicolumn{3}{|l|}{ Sequencing } \\
\hline Sal Hin $2.2 \mathrm{~F}$ & TTC TTA TTC TTC CAG GAT TTG GA & \\
\hline Sal Hin 2.2 F1 & TTG CTA TTA TAG GGG GAT TTG TT & \\
\hline Sal Hin $2.2 \mathrm{R} 1$ & TTG GTT ATA TAA TTG ACT TGA & \\
\hline Sal Hin $2.2 \mathrm{R}$ & GGC TTT AAC TGT TAA GTG AGG AT & \\
\hline Sal AT8 F1 & CCC GCT AAT AGG CCT TGC CCT T & \\
\hline Sal Eco1.3 R & TTT AGA AGT CTA GAA TTT TGG CCT & \\
\hline \multicolumn{3}{|c|}{ IUB code: $R(A / G), Y(C / T), W(A / T), K(G / T)$. } \\
\hline \multicolumn{3}{|c|}{ 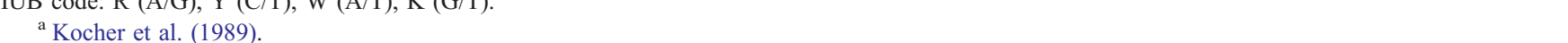 } \\
\hline \multicolumn{3}{|c|}{ b Zardoya and Meyer (1997). } \\
\hline \multicolumn{3}{|c|}{ 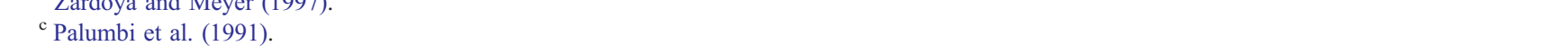 } \\
\hline \multicolumn{3}{|c|}{$\begin{array}{l}\text { Palumbi et al. (1991). } \\
\text { d Arevalo et al. (1994). }\end{array}$} \\
\hline
\end{tabular}


$12 \mathrm{~s} \quad \mathrm{RRNA} \rightarrow$

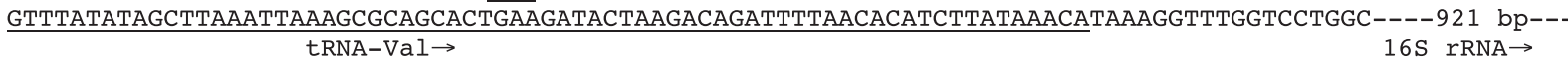
-AAGGTGGACTTGGAATATCAACTTGTAGCTTAATCAAATCATCTTGCTTACACCAAGAAAATACCTGTTAAACCCGGGTCAAGTTGAGTTTTAATTCTA tRNA-LEU (UUR) $\rightarrow$

GCCACA----1567 bp----CCCAAGATCAGGGGGTTAGTTAAGATGGCAGAGCCCGGTAATTGCAAAAGACCTAAGCCCTTTCAATCAGAGGTTCAAC $\mathrm{NADH} 1 \rightarrow$

M $\quad \mathrm{H} \quad \mathrm{L} \quad \mathrm{L} \quad \mathrm{S} \quad \mathrm{S}$ G I $\quad$ P $\quad P \quad M \quad F \quad$ tRNA-Ile $\rightarrow$

TCСтCTTCTTAACTATGCATCTACTATCTTCA----970 bp----GGAATTCCCCCAATATTTTAGGATATGTGCCCGAAAGATAGGAATTACTTTGAT

AGAGTAATTTATAGAGGTTCAAACCCTCTCGTCTCCTTATTAAAAATATAGGACTCGAACCTACCCAGAGGAGATCAAAACCCCTCGTGCTCCCACTACA $\leftarrow$ tRNA-Gln

tRNA-Met $\rightarrow$

$\mathrm{NADH} 2 \rightarrow$

$\begin{array}{llllllllll}M & S & P & Y & V & L\end{array}$

CCACTTTTTAAGTAAAATAAGCTAATTAAGCTTTTGGGCCCATACCCCAAATATGTTGGTTAAACCCCTTCTTATACTAATGAGCCCATATGTGTTA---

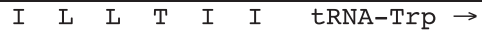

-1036 bp----АTTCTACTAACAATTATTTAAAGACTTAGGATAACTAGACCAAAGACCTTCAAAGTCTTAAGCAGGAGTTAAAATCTTCTAGTCTTTG $\leftarrow$ tRNA-Ala

ATAAGACCTGCAGGACTCTATCCAACATATTCTGAATGCAACCCAGACACTTTAATTAAGCTAAGACCTTCTAGATTAGCAGCTCCTACCCTACGACCTT $\leftarrow$ tRNA-Asn

TTAGTTAACAGCTAAACGCTCCATCCTACGAGCTTTAATCTACTTCTCCCGCTTGTTGGAGAAAAAAAAGCGGGAGAAGCCCCGGCAGAAGCTATCTGCT $\leftarrow$ tRNA-CYS

СTTTAAAATTTGCAATTTTATATGCTGAACATCACAGGACTTGATAAAAAAAGGACTCTAACCTTTATGACAGGAGCTACAATCCTACACCTGCTTCGGC $\mathrm{COI} \rightarrow$

$\leftarrow$ tRNA-TyY M $\quad M \quad I \quad T \quad R \quad$ W

T Y Q Q $\mathrm{E}$ *

САTTTTACCAGTGATAATCACTCGATGA----1560 bp----ACATATCAACAAGAAAGGAGGGAATTGAACCCCCTTAAGTTGATTTCAAGTCAATTA

$\leftarrow$ tRNA-Ser (UCN) tRNA-Asp $\rightarrow$

$\mathrm{COII} \rightarrow$

TATAACCAATCTATTACTCTCTTGAGACATTAGTAAAACTATTACAAGGCCTTGTCAAGACCTAATCATAAGTTAAAATCTTATATGTCTTATATGGCTC $\begin{array}{lllllllllll}P & S & Q & S & S & M & \text { L } & \text { G } & \text { L } & \text { tRNA-LYS } \rightarrow\end{array}$

ACCCGTCACAA----688 bp----TCATCAATGCTAGGACTATCATTAAGAAGCTTTCATACTAAGCAATAGCCTTTTAAGCTAAAGATCGGTGCCCAC

$\begin{array}{llllllllll}M & N & L & N & L & F & & & & \end{array}$

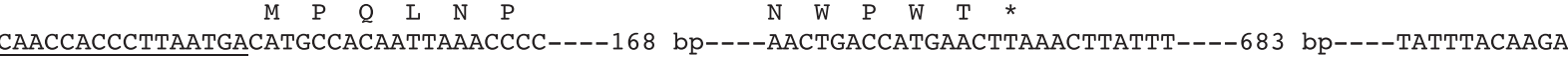

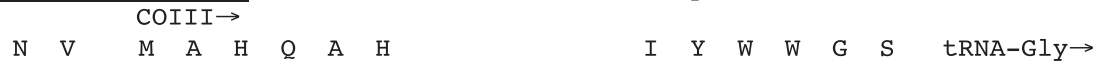

AAACGTATAATGGCACACCAAGCACAC----784 bp----ATTTACTGATGAGGATCATGTCTTTTTAGTATAATAGTACGAATGACTTCCAATCATTA $\mathrm{NADH} 3 \rightarrow$

$M \quad N \quad L \quad I \quad T \quad I$

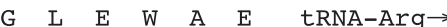

AATCTTAGTCATAATCTAAGAAAAGACAGTGAACTTAATTACACTA----347 bp----GGCCTTGAATGGGCTGAATGAGTATTTAGTCTAAATAAGA

$\mathrm{NADH} \quad 4 \mathrm{~L} \rightarrow$

NADH $4 \rightarrow$

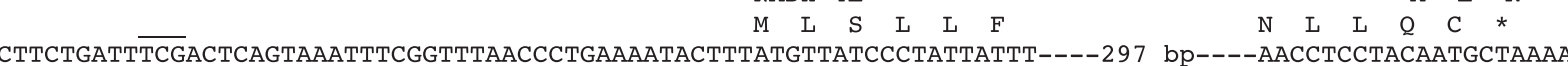

M L K

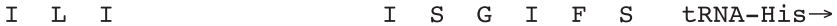

АTTCTGATT----1378 bp----ATCTCCGGGATTTTTTCGTGTGTGCATAATTTAGATAAAATATTAGATTGTGGTTCTAAAAACGAGGGTTAAACCC tRNA-Ser (AGY)

CCCCTTCACACCGAGAGGAGTCAAGAGACTCAGAAACTGCTAACTATCTGCCTCTGCGGTTAAAATCCGCAGTCCCCTCACTTTTAAAGGATAATAGTAA $\mathrm{NADH} 5 \rightarrow$

$\begin{array}{llllllllll}M & N & L & V & L & T\end{array}$

T $S$ Y C P R

TCCATTGGTTTTAGGAACCAAAAATTCTTGGTGCAACCCCGAGTAAAAGTTATGAATCTCGTATTAACG----1815 bP----ACATCTTACTGCCCGT $\leftarrow \mathrm{NADH} 6$

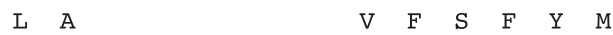

AATGCAC----516 bp----TACAAAACTAAAATAGATCACTATCTTTACCTGGACTCTAACCAAGACCTTTGACCTGAAAAATCAATGTTGTATTCAA Cyt $\mathrm{b} \rightarrow$

$\leftarrow$ tRNA-GIU M СTATAAAAACAATGGCCCACACCCTACGA----1141 bp----AATAAATTAATAAAATGATACCCAGGTAGTTTAAGTAAAACATCGGTCCTGTAAGC

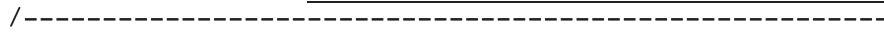
CGAAAACTGAAGATTAAAACCTTCTCTGAGTTAAGCCAGGACCCCAACCAATAAACACCACCAATCCATTATTTCTCTTTTTGCCCGGGCTCCGCCAATT

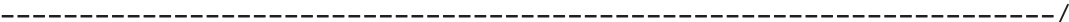

TCAAACACACCGAAAAGAGTCTTACTTTCTCTAAAAATCCACAAACAAACCATCACGTATTAAATTTTATAGTTGGGGGAACTCCTCCTCCAAGCTCTTC

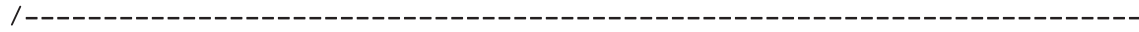

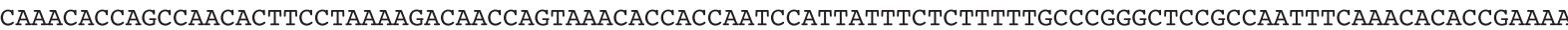

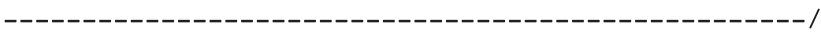

GAGTCTCACTCTCTCTAAAAATCCACAAACAAACCATCACACATTAAATTTTTCAAAAGGGGGGGAATTTCACCTCCGCCACTGGCACCCAAGGCCAAAA $\leftarrow$ tRNA-Procontrol region $\rightarrow$

TTCTAGACTTCTAAACTACCTCTCGCTCTATTTTCCTAAGATTTCATTT----922 bp----TAATAAATATTTGCTATATTACAATATTACATTATAA

Fig. 1. Schematic representation of the L-strand nucleotide sequence of the salamander mitochondrial genome. Position 1 corresponds to the first nucleotide of the $t R N A-P h e$ gene. Direction of transcription for each gene is represented by arrows. The beginning and end of the deduced amino acid sequence for each gene product are shown above the nucleotide sequence (one-letter amino acid abbreviation is placed above the first nucleotide of each codon). Complete termination codons are indicated by an asterisk. Total lengths of each protein-coding gene are shown. tRNA genes are underlined and the corresponding anticodons are overlined. Two repeats are shown between tRNA-Thr and tRNA-Pro genes. 
template source. To this end, highly conserved (Kocher et al., 1989; Palumbi et al., 1991; Moritz et al., 1992; Arevalo et al., 1994; Zardoya and Meyer, 1997), and newly designed PCR primers (Table 1) were used to amplify up to 16 contiguous and overlapping fragments. The PCR amplification was conducted in $25 \mu \mathrm{l}$ reactions containing $67 \mathrm{mM}$ Tris- $\mathrm{HCl}, \mathrm{pH} 8.3,1.5 \mathrm{mM} \mathrm{MgCl} 2,0.4 \mathrm{mM}$ of each dNTP, $2.5 \mu \mathrm{M}$ of each primer, template mtDNA (10-100 ng), and Taq DNA polymerase (1 unit, Promega), using the following program: 1 cycle of $2 \mathrm{~min}$ at $94{ }^{\circ} \mathrm{C}, 35$ cycles of $60 \mathrm{~s}$ at $94{ }^{\circ} \mathrm{C}, 60 \mathrm{~s}$ at $45-50{ }^{\circ} \mathrm{C}$, and $60-105 \mathrm{~s}$ at $72{ }^{\circ} \mathrm{C}$, and finally, 1 cycle of $5 \mathrm{~min}$ at $72{ }^{\circ} \mathrm{C}$. PCR fragments were cloned into the pGEM-T vector (Promega).

Recombinant plasmids were sequenced using the FS-Taq Dye Deoxy Terminator cycle-sequencing kit (Applied Biosystems) on Applied Biosystems automated DNA sequencers (373A Stretch and 377) following manufacturer's protocols. DNA sequences of both strands were obtained using M13 universal (forward and reverse) sequencing primers. The sequences obtained from each clone averaged $450 \mathrm{bp}$ in length and each sequence overlapped the next contig by about $100 \mathrm{bp}$. In no case were differences in sequence observed between the overlapping regions.

\subsection{Molecular and phylogenetic analyses}

Sequence data were analyzed with the GCG program package (Devereux et al., 1984), MacClade version 3.06 (Maddison and Maddison, 1992), and PAUP* version 4.0b8 (Swofford, 1998). The average frequency of the different amino acid replacements for the main lineages of vertebrates was estimated with the CHART STATE CHANGES and STASIS option in MacClade based on the species used in the phylogenetic analyses (Appendix A).

To reconstruct a phylogeny of gnathostomes, the deduced amino acid sequences of all salamander mitochondrial protein-coding genes (except ND6) were aligned to homologous sequences of other representative vertebrates (Appendix A) using CLUSTAL W (Thompson et al., 1994). Alignments were refined by eye and gaps were treated as missing data. Ambiguous alignments were determined using the Gblocks v0.73b program (Castresana, 2000) and were excluded from the phylogenetic analyses.

The data set was analyzed with maximum parsimony (MP), minimum evolution (ME), maximum likelihood (ML), and Bayesian methods of phylogenetic inference. MP analyses (PAUP* version 4.0b8; Swofford, 1998) were performed using heuristic searches (TBR branch swapping; MulTrees option in effect) with 10 random stepwise addi- tions of taxa. ME analyses (Rzhetsky and Nei, 1992) were performed using mean distances in PAUP* version $4.0 \mathrm{~b} 8$ (Swofford, 1998). ML analyses were performed in PUZZLE version 4.0.1 (Strimmer and von Haeseler, 1996) using the mtREV model (Adachi and Hasegawa, 1996). Bayesian analysis was performed in MrBayes version 2.01 (Huelsenbeck and Ronquist, 2001) using the JTT model (Jones et al., 1992). Robustness of the inferred trees was tested by non-parametric bootstrapping (Felsenstein, 1985), quartet puzzling, and Bayesian posterior probability analyses, as implemented in PAUP*, PUZZLE, and MrBayes with 500 pseudoreplications, 1000 quartet puzzling steps, and 100,000 generations, respectively.

Constancy of rates of evolution among vertebrates was estimated with a log likelihood ratio test and the mtREV model (Adachi and Hasegawa, 1996) by using PUZZLE version 4.0.1 (Strimmer and von Haeseler, 1996). To determine which groups were evolving at significantly different rates, a relative ratio test with Poisson-corrected distances was performed by using Phyltest version 2.0 (Kumar, 1996).

The complete nucleotide sequence of the salamander $\mathrm{mt}$ genome was deposited in GenBank under accession number AF154053.

\section{Results and discussion}

\subsection{Organization of the salamander mitochondrial genome}

The mitochondrial genome of the salamander M. luschani is $16,650 \mathrm{bp}$ long and conforms to the consensus vertebrate mitochondrial gene order (Fig. 1). As in other vertebrates, 2 rRNAs, 22 tRNAs, and 13 proteins are encoded by the salamander mitochondrial genome (Fig. 1). The overall base composition of the L-strand is A: $32 \%$, T: $29 \%$, C: $24 \%$, and G: $15 \%$. There are only nine noncoding intergenic spacer nucleotides. Interestingly, this paucity of intergenic spacers contrasts with the existence of a long non-coding stretch of $320 \mathrm{bp}$ separating tRNA ${ }^{\text {Thr }}$ and tRNA ${ }^{\text {Pro }}$ genes (Fig. 1). This intervening sequence includes two 124-bp repeats. Both repeats differ in five transitions. No significant matches for the repeat motif were found in a GenBank search, so its evolutionary origin is unknown. Similar cases of intervening noncoding sequences between two tRNAs have been documented in two birds, Falco peregrinus and Smithornis sharpei (Mindell et al., 1998). In both cases, the stretch is located between tRNA ${ }^{\mathrm{Glu}}$ and tRNA ${ }^{\text {Phe }}$ genes. In F. peregrinus, the intervening sequence also contains repeats. Interestingly, in both bird mitochondrial genomes the

\footnotetext{
Fig. 2. Majority rule $(50 \%)$ consensus trees depicting phylogenetic relationships of jawed vertebrates. A data set combining the deduced amino acid sequences of all mitochondrial protein-coding genes (except ND6) and of 36 representative vertebrate taxa was subjected to MP (bootstrap values based on 500 bootstrap pseudoreplications; upper value of each triplet of numbers above the nodes), $\mathrm{NJ}$ (bootstrap values based on 500 bootstrap pseudoreplications; middle value of each triplet of numbers above the nodes), ML (quartet puzzling support values based on 1000 puzzling steps; lower value of each triplet of numbers above the nodes), Bayesian (posterior probabilities based on 100,000 generations; numbers below the nodes) analyses. Cartilaginous fishes were used as outgroup taxa.
} 


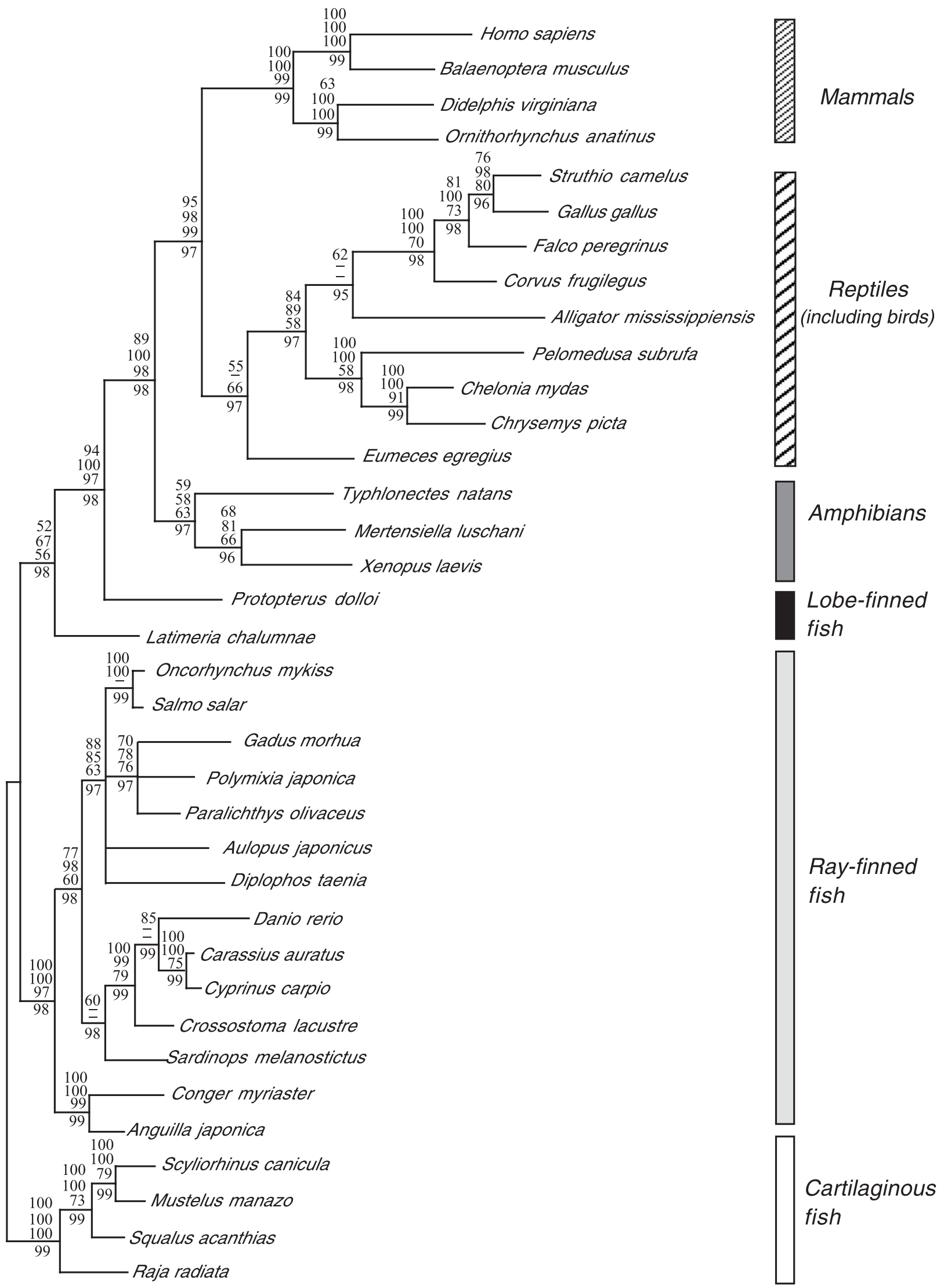


tRNA $^{\text {Thr }}$ and tRNA ${ }^{\text {Pro }}$ genes are separated by the control region. The origin of these rearrangements in the bird mitochondrial genomes seems to be related with the translocation capacity of the involved tRNA genes and their close proximity to the origin of the heavy-strand replication within the control region (Mindell et al., 1998). A similar mechanism might be involved in the origin of the intervening sequence that separates salamander mitochondrial tRNA ${ }^{\text {Thr }}$ and tRNA ${ }^{\text {Pro }}$ genes.

The control region of the salamander mitochondrial genome is 922 bp long. Both conserved sequence blocks (CSB1, CSB-2, and CSB-3; Walberg and Clayton, 1981) and termination-associated sequences (TAS-1 and TAS-2; Doda et al., 1981) were identified in the salamander mitochondrial control region. Interestingly, the salamander CSB-1 shares high similarity to the vertebrate CSB-1 consensus, and it is not reduced to a truncated pentamotif $\left(5^{\prime}\right.$-GACAT- $\left.3^{\prime}\right)$ as in the frog, and the caecilian (Zardoya and Meyer, 2000). As in most vertebrates, the origin of light strand replication $\left(\mathrm{O}_{\mathrm{L}}\right)$ of the salamander mitochondrial genome, is located in a cluster of five tRNA genes (WANCY region) between tRNA ${ }^{\text {Asn }}$ and
tRNA $^{\text {Cys }}$ (Fig. 1) (but see Seutin et al., 1994). This region is 34 nucleotides in length and has the potential to fold into a stem-loop secondary structure (not shown). The folding of the $\mathrm{O}_{\mathrm{L}}$ does not require to use a considerable part of the adjacent tRNA ${ }^{\text {Cys }}$ as has been described for the caecilian (Zardoya and Meyer, 2000). The salamander $\mathrm{O}_{\mathrm{L}}$ loop, as in other tetrapods, contains a stretch of thymines that is needed for the initiation of L-strand synthesis (Wong and Clayton, 1985).

The salamander $12 S$ and $16 S$ rRNA genes are 921 and 1567 nucleotides long, respectively (Fig. 1). Our salamander $12 S$ rRNA gene sequence showed only minor differences (96\% similarity) to that previously reported (Titus and Larson, 1995). The salamander tRNAs ranged in size from 65 to 75 nucleotides, and showed size variability in their DHU and $\mathrm{T} \psi \mathrm{C}$ arms when compared to other vertebrate mitochondrial tRNAs. Most salamander mitochondrial protein-coding genes begin with a ATG start codon. However, COI and ND3 start with GTG, and ND6 with ATC. Most salamander ORFs end with incomplete stop codons, either T (ND1, ND2, COII, COIII, ND3, ND4, and Cyt b) or TA

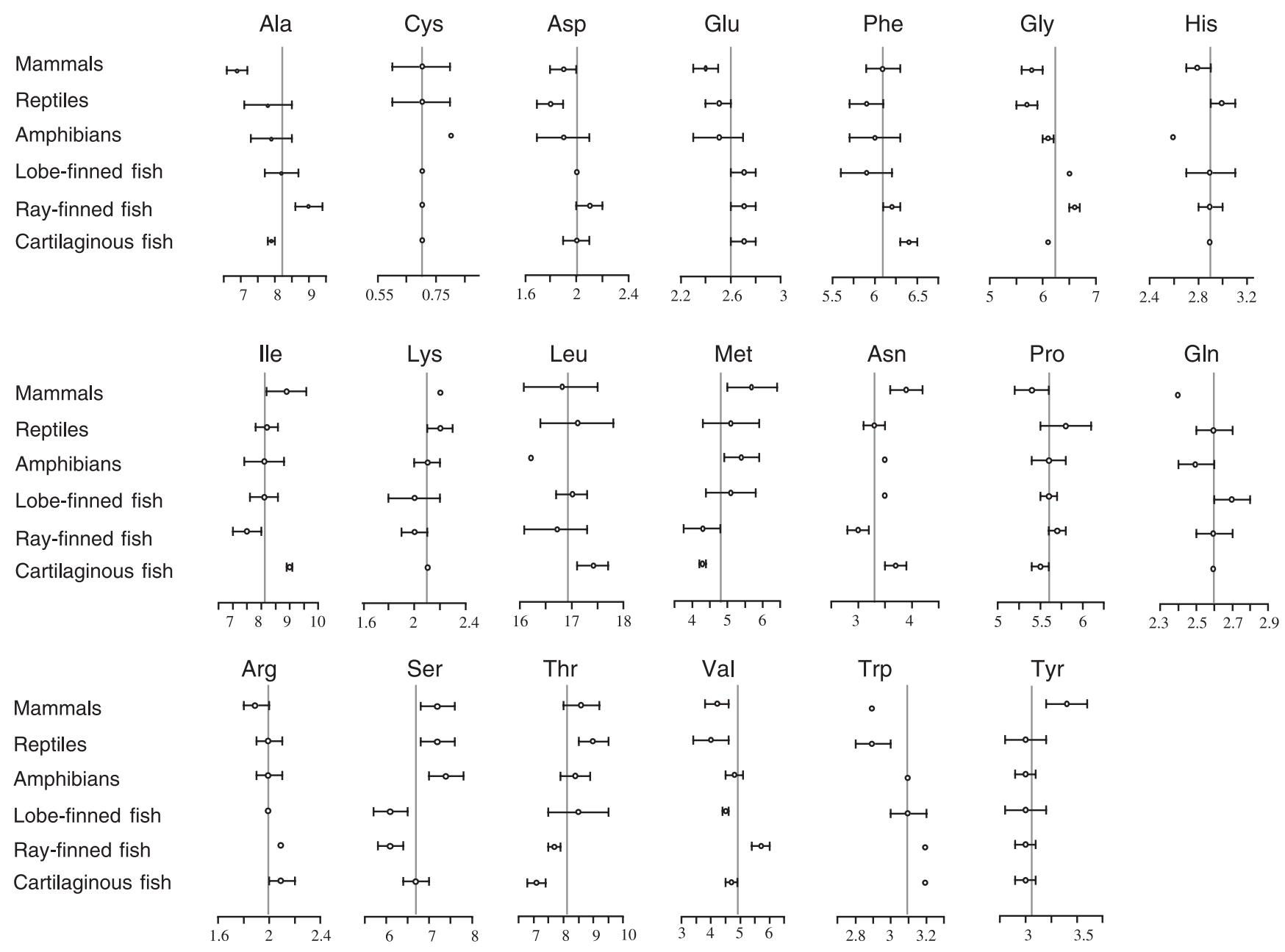

Fig. 3. Mean frequencies (\%) and standard deviations of the different amino acids in the main lineages of vertebrates. The grey bars indicate the estimated empirical amino acid frequencies incorporated into the evolutionary model used for the phylogenetic analyses. 
(ATPase 6). COI ends with AGG, ND6 with AGA, and ATPase 8, ND4L, and ND5 with TAA.

\subsection{Phylogenetic relationships among jawed vertebrates}

The deduced amino acid sequences of all mitochondrial protein-coding genes (except ND6) of 36 representative vertebrate taxa (see Appendix A) were combined into a single data set. We did not include Rana nigromaculata (Sumida et al., 2001) in the analyses because this species has a extremely long branch that produces phylogenetic reconstruction artifacts (results not shown). An alignment of 3676 positions was produced. A total of 416 positions were excluded because of ambiguity, 1176 were invariant, and 1609 were parsimony-informative. One single most parsimonious tree of 13,355 steps was recovered when cartilagionous fishes were used as outgroup (Fig. 2). In this tree, eels are the most basal lineage within a monophyletic teleost group (Inoue et al., 2001b; Miya et al., 2001), lungfishes are the sister group of tetrapods (Zardoya et al., 1998), and amphibians are recovered as a monophyletic group at the base of tetrapods (Zardoya and Meyer, 2001). Moreover, turtles show diapsid affinities and are placed as the sister group of archosaurs (crocodiles and birds) (Zardoya and
Meyer, 1998; Kumazawa and Nishida, 1999), and marsupials and monotremes form a monophyletic group (Janke et al., 1996) (Fig. 2). Among amphibians, a sistergroup relationship of salamanders and frogs (the Batrachia hypothesis) to the exclusion of caecilians is recovered (Zardoya and Meyer, 2001) (Fig. 2). ME, ML, and Bayesian phylogenetic analyses arrived at similar and congruent topologies (Fig. 2 ). The robustness of the results was confirmed by high bootstrap (quartet puzzling and Bayesian posterior probability) support of most of the nodes in the tree (Fig. 2).

Most of the phylogenetic relationships recovered in the molecular tree are in agreement with current morphological and paleontological evidence. The basal position of anguilliformes within teleosts is well supported by morphological data (Nelson, 1994). Despite there has been a long-standing controversy on which is the closest living sister group of tetrapods, the latest morphological and paleontological analyses favor lungfishes as the closest relatives of tetrapods (Cloutier and Ahlberg, 1997). Most phylogenetic analyses based on morphological characters support the batrachia hypothesis (Trueb and Cloutier, 1991). Traditionally, turtles have been considered the only survivors of anapsid reptiles. However, recent studies based on reptile morphology strongly support the diapsid affinities of turtles (Rieppel
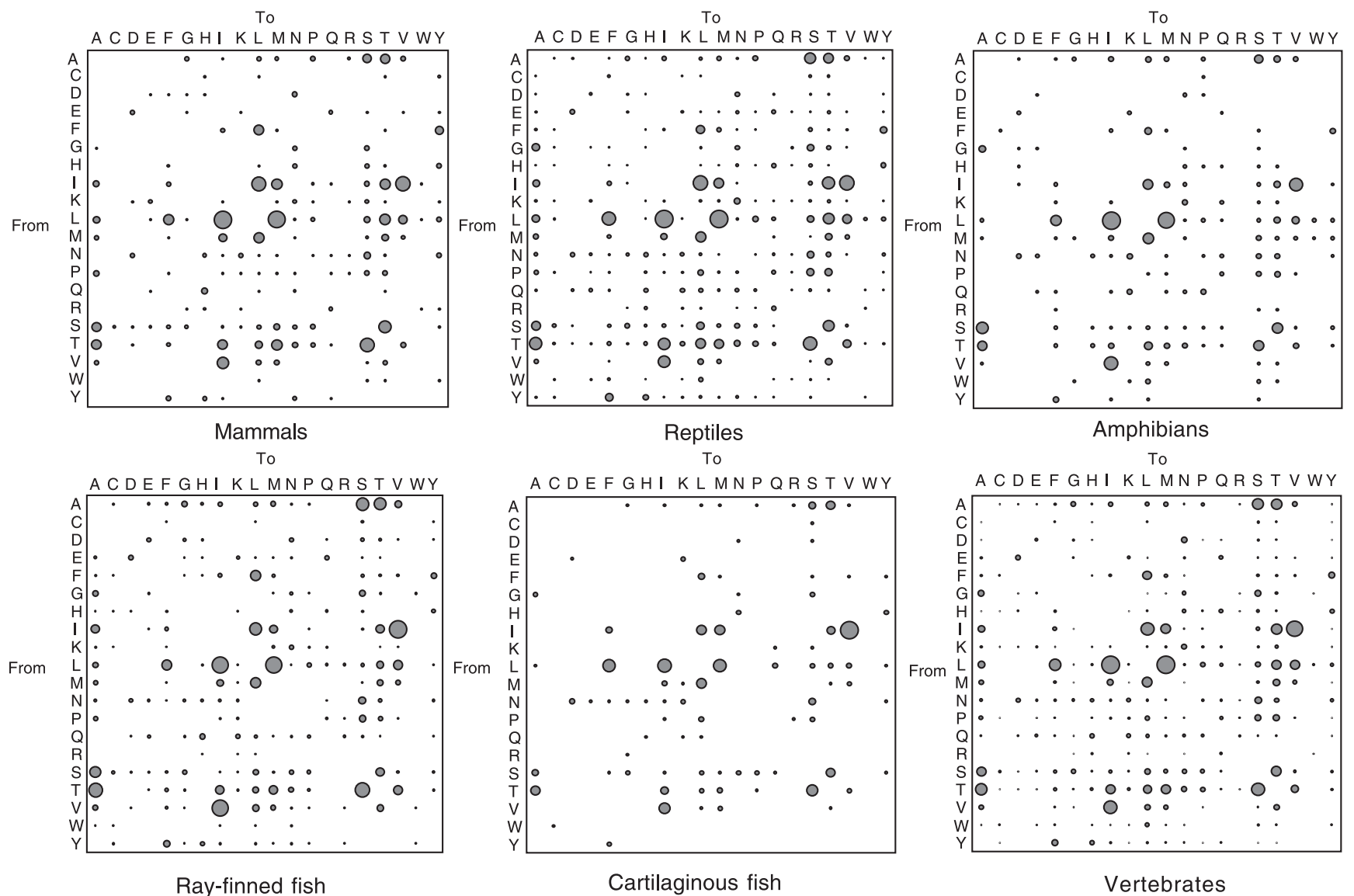

Fig. 4. The average frequency of different amino acid replacements for the main lineages of vertebrates. The diameter of the largest circle equals 485 changes and other circles are scaled in diameter proportionally. 


\begin{tabular}{|c|c|c|c|c|c|c|c|c|c|c|c|c|c|c|}
\hline A & Mammals & Reptiles & Amphibians & Lobe-finned & Ray-finned & & B & Homo & Balaenoptera & Didelphis & Ornithorhynchus & & & \\
\hline Mammals & - & & & & & & Homo & - & & & & & & \\
\hline Reptiles & $2.29^{\star}$ & - & & & & & Balaenoptera & $5.24^{\star}$ & - & & & & & \\
\hline Amphibians & $9.35^{*}$ & $8.71^{*}$ & - & & & & Didelphis & $3.69^{\star}$ & 1.09 & - & & & & \\
\hline Lobe-finned fish & $13.45^{*}$ & $13.38^{*}$ & $5.89^{*}$ & - & & & Ornithorhynchus & $3.92^{*}$ & 0.84 & 0.31 & - & & & \\
\hline Ray-finned fish & $18.91^{\star}$ & $20.47^{\star}$ & $13.57^{\star}$ & $7.80^{*}$ & - & & & & & & & & & \\
\hline c & Struthio & Gallus & Falco & Corvus & Alligator & Pelomedusa & Chelonia & Chrysemis & Eumeces & & D & Typhlonectes & Mertensiella & Xenopus \\
\hline Struthio & - & & & & & & & & & & Typhlonectes & & & \\
\hline Gallus & $2.12^{\star}$ & - & & & & & & & & & Mertensiella & $3.43^{*}$ & - & \\
\hline Falco & 1.78 & 1.92 & - & & & & & & & & Xenopus & $3.48^{*}$ & 0.09 & - \\
\hline Corvus & 0.48 & 1.38 & 0.42 & - & & & & & & & & & & \\
\hline Alligator & $7.02^{*}$ & $6.00^{*}$ & $7.07^{*}$ & $6.78^{*}$ & - & & & & & & & & & \\
\hline Pelomedusa & $7.18^{*}$ & $5.97^{*}$ & $7.07^{\star}$ & $6.87^{\star}$ & 0.15 & - & & & & & $E$ & Protopterus & Latimeria & \\
\hline Chelonia & $3.51^{*}$ & $4.86^{*}$ & $3.51^{*}$ & $3.72^{*}$ & $10.3^{*}$ & $11.22^{*}$ & - & & & & Protopterus & - & & \\
\hline Chrysemis & 0.61 & 0.64 & 0.60 & 0.30 & $6.48^{*}$ & $7.22^{*}$ & $5.81^{*}$ & - & & & Latimeria & $4.01^{*}$ & - & \\
\hline Eumeces & $3.06^{*}$ & $4.26^{*}$ & $2.98^{*}$ & $3.32^{*}$ & $9.40^{*}$ & $9.76^{*}$ & 0.37 & $3.63^{*}$ & - & & & & & \\
\hline$F$ & Oncorhynchus & Salmo & Gadus & Paralichthys & Polymixia & Aulopus & Diplophos & Danio & Carassius & Cyprinus & Crossostoma & Sardinops & Conger & Anguilla \\
\hline Oncorhynchus & - & & & & & & & & & & & & & \\
\hline Salmo & $2.19^{*}$ & - & & & & & & & & & & & & \\
\hline Gadus & $4.61^{*}$ & $5.44^{*}$ & - & & & & & & & & & & & \\
\hline Paralichthys & $4.40^{*}$ & $5.35^{*}$ & 0.22 & - & & & & & & & & & & \\
\hline Polymixia & 1.43 & $2.53^{*}$ & $3.72^{*}$ & $3.49^{*}$ & - & & & & & & & & & \\
\hline Aulopus & 1.47 & $2.57^{\star}$ & $3.54^{\star}$ & $3.29^{*}$ & 0.62 & - & & & & & & & & \\
\hline Diplophos & 4.23 & $5.19^{*}$ & 0.61 & 0.40 & $2.91^{*}$ & $2.89^{*}$ & - & & & & & & & \\
\hline Danio & $5.18^{\star}$ & $5.97^{\star}$ & 1.12 & 1.35 & 4.16 & $4.15^{*}$ & 1.69 & - & & & & & & \\
\hline Carassius & 1.17 & 0.20 & $5.30^{*}$ & $5.19^{*}$ & $2.51^{*}$ & $2.42^{*}$ & $4.79^{*}$ & $7.23^{*}$ & - & & & & & \\
\hline Cyprinus & 0.44 & 1.40 & $3.82^{\star}$ & $3.72^{\star}$ & 0.83 & & $3.29^{*}$ & $5.50^{\star}$ & $3.57^{*}$ & - & & & & \\
\hline Crossostoma & $2.48^{*}$ & 3.48 & $2.03^{*}$ & 1.81 & 1.25 & 1.22 & 1.44 & $3.43^{*}$ & $4.56^{*}$ & $2.51^{\star}$ & - & & & \\
\hline Sardinops & $2.83^{*}$ & $3.88^{*}$ & 1.82 & 1.66 & 1.54 & 1.55 & 1.27 & $2.93^{*}$ & $3.97^{*}$ & $2.32^{*}$ & 0.24 & - & & \\
\hline Conger & $5.26^{*}$ & $6.13^{\star}$ & 1.06 & 1.26 & $4.25^{*}$ & $4.18^{*}$ & 1.65 & 0.09 & $6.21^{*}$ & $4.74^{*}$ & $3.09^{*}$ & $2.78^{*}$ & - & \\
\hline Anguilla & 0.93 & 1.91 & $3.52^{*}$ & $3.27^{\star}$ & 0.32 & 0.31 & $2.91^{*}$ & $4.50^{*}$ & $2.09^{*}$ & 0.50 & 1.54 & 1.74 & $5.23^{*}$ & - \\
\hline
\end{tabular}

Fig. 5. Evolutionary rates of the main lineages of vertebrates and their corresponding members. The $Z$ statistics of the relative rate tests performed among (A) and within main lineages of vertebrates (B, mammals; C, reptiles; D, amphibians; E, lobe-finned fish; F, ray-finned fish) are shown. An asterisk denotes those cases in which rate constancy was rejected at the $5 \%$ significance level. 
and deBraga, 1996). The only important conflict between molecules and morphology is on the phylogenetic relationships of mammals. Mitochondrial data support a close sister group relationship of marsupials and monotremes, the marsupionta hypothesis (Gregory, 1947), whereas most paleontological and morphological data favor a close relationships of marsupials and placental mammals to the exclusion of monotremes (Carroll, 1988). Recently, a large nuclear gene, the mannose 6-phosphate/insulin-like growth factor II receptor, was isolated and sequenced from various representatives of monotremes, marsupials, and placental mammals (Killian et al., 2001). Nuclear gene sequence data support marsupials as the sister group of placentals to the exclusion of monotremes (Killian et al., 2001).

Our results reject earlier phylogenetic studies based on mitochondrial sequence data that used lamprey or hagfish as outgroup taxa, and recovered rather unorthodox vertebrate phylogenies (Rasmussen and Arnason, 1999a,b). Strong support of the vertebrate tree both from morphology and molecules provides a phylogenetic framework that will be helpful in interpreting the results of many comparative studies of living vertebrates.

\subsection{Comparative vertebrate mitogenomics}

The average frequencies of different amino acids for each of the main lineages of jawed vertebrates are shown in Fig. 3. Leucine is the most abundant amino acid in mitochondrial proteins, whereas cysteine is the rarest. The relative frequency of amino acids in mitochondrial proteins is in agreement with their hydrophobic properties and membrane location (Naylor et al., 1995). The relative proportion of Ile, Lys, Met, Ser, and Thr in mitochondrial proteins increases from fish to mammals. In contrast the relative frequency of Ala, Glu, Gly, Arg, and Trp in mitochondrial proteins apparently decreases from fish to mammals. The remaining amino acids maintain stable frequencies among vertebrates. Cartilaginous fishes showed the least variation in amino acid frequencies.

Amino acid replacements were found to be relatively constant among main vertebrate lineages (Fig. 4) and might indicate functional and structural constraints of mitochondrial proteins. The most frequent amino acid changes were Leu to Ile, leu to Met, Ile to Val, Val to Ile, Ala to Ser, and Thr to Ser. Cys and Arg are barely replaced in vertebrates. Almost no amino acid replacement yields Trp. Amino acid replacements were less frequent in cartilaginous fishes compared to other vertebrates. This phenomenon may be directly related to the observed slow rates of evolution of shark mitochondrial proteins (Martin et al., 1992).

Evolutionary rate constancy among the main vertebrate lineages was tested. A log likelihood ratio test between the most likely trees with and without the assumption of a molecular clock was performed. The clock-like tree was rejected on a significant level of $5 \%$. None of the main lineages of vertebrates evolve at the same rate (Fig. 5A).
Moreover, most of the vertebrate taxa analyzed show heterogeneous rates of evolution (Fig. 5B-E). Hence, it was not possible to estimate divergence dates for the main lineages of vertebrates under the assumption of a molecular clock.

In conclusion, we have determined the complete sequence of the mitochondrial genome of a salamander and used it to infer phylogenetic relationships among the main lineages of vertebrates and to characterize general trends in the molecular evolution of vertebarte mitochondrial proteins. Our results show slight differences in amino acid frequencies of mitochondrial proteins among vertebrate main lineages but a fairly constant amino replacement pattern across all vertebrate groups. Moreover, vertebrate taxa are characterized by significantly different rates of evolution with few exceptions. Despite these putative biases, phylogenetic inference based on different methods and a combined mitochondrial amino acid sequence data set recovered a strongly supported vertebrate phylogeny that is in agreement with morphological and paleontological evidence.

\section{Acknowledgements}

Meredith J. Mahoney gave very useful advice on primers and PCR conditions to amplify the salamander ND4 gene. We thank two anonymous reviewers for their useful comments on an earlier version of the paper. R.Z. was sponsored by a postdoctoral contract of the Ministerio de Educacion y Cultura of Spain. This work received partial financial support from grants from the Lion Foundation, the Deutsche Forschungs Gemeinschaft (ME 1725/4-1), the University of Konstanz, the US National Science Foundation (DEB-9615178) to AM, and the Spanish Ministerio de Ciencia y Tecnología to RZ (REN2001-1514/GLO).

\section{Appendix A}

Phylogenetic analyses of jawed vertebrate relationships included the following 36 complete vertebrate mitochondrial DNA genomes: Raja, Raja radiata (AF106038, Rasmussen and Arnason, 1999b); spiny dogfish, Squalus acanthias (Y18134, Rasmussen and Arnason, 1999a); gummy shark, Mustelus manazo (AB015962, Cao et al., 1998); dogfish, Scyliorhinus canicula (Y16067, Delarbre et al., 1998); Japanese eel, Anguilla japonica (AB038556, Inoue et al., 2001a); conger eel, Conger myriaster (AB038381, Inoue et al., 2001b); Japanese sardine, Sardinops melanostictus (AB032554, Inoue et al., 2000); rainbow trout, Oncorhynchus mykiss (L29771, Zardoya et al., 1995); Atlantic salmon, Salmo salar (U12143, Hurst et al., 1999); codfish, Gadus morhua (X99772, Johansen and Bakke, 1996); carp, Cyprinus carpio (X61010, Chang et al., 1994); loach, Crossostoma lacustre (M91245, Tzeng et al., 1992); gold- 
fish, Carassius auratus (AB006953, Murakami et al., 1998); zebrafish, Danio rerio (AC024175, J.E. Milam, R.E. Broughton, and B.A. Roe, unpublished); Japanese flounder, Paralichthys olivaceus (AB028664, Saitoh et al., 2000); Japanese thread-sail fish, Aulopus japonicus (AB047821, Kawaguchi et al., 2001); Pacific portholefish, Diplophos taenia (AB034825, Miya and Nishida, 2000); silvereye fish, Polymixia japonica (AB034826, Miya and Nishida, 2000); African lungfish, Protopterus dolloi (L42813, Zardoya and Meyer, 1996); coelacanth, Latimeria chalumnae (U82228, Zardoya and Meyer, 1997); clawed frog, Xenopus laevis (M10217, Roe et al., 1985); caecilian, Typhlonectes natans (AF154051, Zardoya and Meyer, 2000); salamander, M. luschani (AF154053, Zardoya and Meyer, 2001 and this work); skink, Eumeces egregius (AB016606, Kumazawa and Nishida, 1999); side-necked turtle, Pelomedusa subrufa (AF039066, Zardoya and Meyer, 1998); green turtle, Chelonia mydas (AB012104, Kumazawa and Nishida, 1999); painted turtle, Chrysemys picta (AF069423, Mindell et al., 1999); alligator, Alligator mississippiensis (Y13113, Janke and Arnason, 1997); ostrich, Struthio camelus (Y12025, Härlid et al., 1997); Falcon, F. peregrinus (AF090338, Mindell et al., 1999); Rook, Corvus frugilegus (Y18522, Härlid and Arnason, 1999); chicken, Gallus gallus (X52392, Desjardins and Morais, 1990); platypus, Ornithorhynchus anatinus (X83427, Janke et al., 1996); opossum, Didelphis virginiana (Z29573, Janke et al., 1994); blue whale, Balaenoptera musculus (X72204, Arnason and Gullberg, 1993); and human, Homo sapiens (D38112, Horai et al., 1995).

\section{References}

Adachi, J., Hasegawa, M., 1996. Model of amino acid substitution in proteins encoded by mitochondrial DNA. J. Mol. Evol. 42, 459-468.

Arevalo, E., Davis, S.K., Sites, J.W., 1994. Mitochondrial DNA sequence divergence and phylogenetic relationships among eight chromosome races of the Sceloporus grammicus complex (Phrynosomatidae) in Central Mexico. Syst. Biol. 43, 387-418.

Arnason, U., Gullberg, A., 1993. Comparison between the complete mtDNA sequences of the blue and the fin whale, two species that can hybridize in nature. J. Mol. Evol. 37, 312-322.

Cao, Y., Waddell, P.J., Okada, N., Hasegawa, M., 1998. The complete mitochondrial DNA sequence of the shark Mustelus manazo: evaluating rooting contradictions to living bony vertebrates. Mol. Biol. Evol. 15, $1637-1646$.

Carroll, R.L., 1988. Vertebrate Paleontology and Evolution. Freeman, New York.

Castresana, J., 2000. Selection of conserved blocks from multiple alignments for their use in phylogenetic analysis. Mol. Biol. Evol. 17, $540-552$.

Chang, Y.S., Huang, F.L., Lo, T.B., 1994. The complete nucleotide sequence, gene organization of carp (Cyprinus carpio) mitochondrial genome. J. Mol. Evol. 38, 138-155.

Cloutier, R., Ahlberg, P.E., 1997. Interrelationships of basal sarcopterygians. In: Stiassny, M.L.J., Parenti, L.R., Johnson, G.D. (Eds.), Interrelationships of Fishes. Academic Press, San Diego, CA, USA, pp. $445-479$

Delarbre, C., Spruyt, N., Delmarre, C., Gallut, C., Barriel, V., Janvier, P.,
Laudet, V., Gachellin, G., 1998. The complete nucleotide sequence of the mitochondrial DNA of the dogfish, Scyliorhinus canicula. Genetics 150, 331-344.

Desjardins, P., Morais, R., 1990. Sequence and gene organization of the chicken mitochondrial genome. J. Mol. Biol. 212, 599-634.

Devereux, J., Haeberli, P., Smithies, O., 1984. A comprehensive set of sequence analysis programs for the VAX. Nucleic Acids Res. 12, $387-395$.

Doda, J.N., Wright, C.T., Clayton, D.A., 1981. Elongation of displacement loop strands in human and mouse mitochondrial DNA is arrested near specific template sequences. Proc. Natl. Acad. Sci. U. S. A. 78, $6116-6120$.

Duellman, W.E., Trueb, L., 1994. Biology of Amphibians. Johns Hopkins Univ. Press, Baltimore.

Felsenstein, J., 1985. Confidence limits on phylogenies: an approach using the bootstrap. Evolution 39, 783-791.

Frost, D.R.E., 1985. Amphibian Species of the World. A Taxonomic and Geographical Reference. Allen Press and Association of Systematics Collections, Lawrence.

Gregory, W.K., 1947. The monotremes and the palimpsest theory. Bull. Am. Mus. Nat. Hist. 88, 1-52.

Härlid, A., Arnason, U., 1999. Analyses of mitochondrial DNA nest ratite birds within the Neoagnathae: supporting a neotenous origin of ratite morphological characters. Proc. R. Soc. Lond. B 266, 305-309.

Härlid, A., Janke, A., Arnason, U., 1997. The mtDNA sequence of the ostrich and the divergence between paleognathous and neognathous birds. Mol. Biol. Evol. 14, 754-761.

Horai, S., Hayasaka, K., Kondo, R., Tsugane, K., Takahata, N., 1995. Recent African origin of modern humans revealed by complete sequences of hominoid mitochondrial DNAs. Proc. Natl. Acad. Sci. U. S. A. $92,532-536$.

Huelsenbeck, J.P., Ronquist, F.R., 2001. MrBayes: bayesian inference of phylogeny. Bioinformatics 17, 754-755.

Hurst, C.D., Bartlett, S.E., Davidson, W.S., Bruce, I.J., 1999. The complete mitochondrial DNA sequence of the Atlantic salmon, Salmo salar. Gene 239, 237-242.

Inoue, J.G., Miya, M., Tsukamoto, K., Nishida, M., 2000. Complete mitochondrial DNA sequence of the Japanese sardine Sardinops melanostictus. Fish. Sci. 66, 924-932.

Inoue, J.G., Miya, M., Nishida, M., 2001a. Complete mitochondrial DNA sequence of the Japanese eel, Anguilla japonica. Fish. Sci. $67,118-125$.

Inoue, J.G., Miya, M., Tsukamoto, K., Nishida, M., 2001b. Complete mitochondrial DNA sequence of Conger myriaster (Teleostei: Anguilliformes): novel gene order for vertebrate mitochondrial genomes and the phylogenetic implications for anguilliform families. J. Mol. Evol. 52, 311-320.

Janke, A., Arnason, U., 1997. The complete mitochondrial genome of Alligator mississipiensis and the separation between recent Archosauria (Birds and crocodiles). Mol. Biol. Evol. 14, 1266-1272.

Janke, A., Feldmaier-Fuchs, G., Thomas, K., Von Haeseler, A., Pääbo, S., 1994. The marsupial mitochondrial genome and the evolution of placental mammals. Genetics 137, 243-256.

Janke, A., Gemmell, N.J., Feldmaier-Fuchs, G., von Haeseler, A., Paabo, S., 1996. The mitochondrial genome of a monotreme-the platypus (Orrnithorhynchus anatinus). J. Mol. Evol. 42, 153-159.

Johansen, S., Bakke, I., 1996. The complete mitochondrial DNA sequence of Atlantic cod, Gadus morhua: relevance to taxonomic studies among cod-fishes. Mol. Mar. Biol. 5, 203-214.

Jones, D.T., Taylor, W.R., Thornton, J.M., 1992. The rapid generation of mutation data matrices from protein sequences. Comp. Appl. Biosci. 8, $275-282$.

Kawaguchi, A., Miya, M., Nishida, M., 2001. Complete mitochondrial DNA sequence of Aulopus japonicus (Teleostei: Aulopiformes), a basal Eurypterygii: longer DNA sequences and higher-level relationships. Ichthyol. Res. 48, 213-223.

Killian, J.K., Buckley, T.R., Stewart, N., Munday, B.L., Jirtle, R.L., 
2001. Marsupials and Eutherians reunited: genetic evidence for the Theria hypothesis of mammalian evolution. Mammal. Genome 12, $513-517$.

Kocher, T.D., Thomas, W.K., Meyer, A., Edwards, S.V., Pääbo, S., Villablanca, F.X., Wilson, A.C., 1989. Dynamics of mitochondrial DNA evolution in animals. Proc. Natl. Acad. Sci. U. S. A. 86, 6196-6200.

Kumar, S., 1996. PHYLTEST: A Program for Testing Phylogenetic Hypothesis. Version 2.0. Institute of Molecular Evolutionary Genetics, The Pennsylvania State University, University Park.

Kumazawa, Y., Nishida, M., 1999. Complete mitochondrial DNA sequences of the green turtle and blue-tailed mole skink: statistical evidence for archosaurian affinity of turtles. Mol. Biol. Evol. 16, 784-792.

Maddison, W.P., Maddison, D.R., 1992. MacClade: Analysis of Phylogeny and Character Evolution. Sinauer Associates, Sunderland.

Martin, A.P., Naylor, G.J.P., Palumbi, S.R., 1992. Rate of mitochondrial DNA evolution is slow in sharks compared to mammals. Nature 357, $153-155$.

Mindell, D.P., Sorenson, M.D., Dimcheff, M.D., 1998. Multiple independent origins of mitochondrial gene order in birds. Proc. Natl. Acad. Sci. U. S. A. $95,10693-10697$.

Mindell, D.P., Sorenson, M.D., Dimcheff, D.E., Hasegawa, M., Ast, J.C., Yuri, T., 1999. Interordinal relationships of birds and other reptiles based on whole mitochondrial genomes. Syst. Biol. 48, 138-152.

Miya, M., Nishida, M., 2000. Use of mitogenomic information in teleostean molecular phylogenetics: a tree-based exploration under the maximum-parsimony optimality criterion. Mol. Phylogenet. Evol. 17, 437-455.

Miya, M., Kawaguchi, A., Nishida, M., 2001. Mitogenomic exploration of higher teleostean phylogenies: a case study for moderate-scale evolutionary genomics with 38 newly determined complete mitochondrial DNA sequences. Mol. Biol. Evol. 18, 1993-2009.

Moritz, C., Schneider, C.J., Wake, D.B., 1992. Evolutionary relationships within the Ensatina eschscholtzii complex confirm the ring species interpretation. Syst. Biol. 41, 273-291.

Murakami, M., Yamashita, Y., Fujitani, H., 1998. The complete sequence of mitochondrial genome from a gynogenetic triploid 'ginbuna' (Carassius auratus langsdorfi). Zool. Sci. 15, 335-337.

Naylor, G.J., Collins, T.M., Brown, W.M., 1995. Hydrophobicity and phylogeny. Nature $373,555-556$.

Nelson, G.J., 1994. Fishes of the World, 3rd ed. Wiley, New York.

Palumbi, S.R., Martin, A., Romano, S., Owen MacMillan, W., Stice, L., Grabowski, G., 1991. The Simple Fool's Guide to PCR. Department of Zoology, University of Hawaii, Honolulu.

Rasmussen, A.F., Arnason, U., 1999a. Phylogenetic studies of complete mitochondrial DNA molecules place cartilaginous fishes within the tree of bony fishes. J. Mol. Evol. 48, 118-123.

Rasmussen, A.S., Arnason, U., 1999b. Molecular studies suggest that cartilagionous fishes have a terminal position in the piscine tree. Proc. Natl. Acad. Sci. U. S. A. 96, 2177-2182.

Rieppel, O., deBraga, M., 1996. Turtles as diapsid reptiles. Nature 384, $453-455$.

Roe, B.A., Din-Pow, M., Wilson, R.K., Wong, J.F., 1985. The complete nucleotide sequence of the Xenopus laevis mitochondrial genome. J. Biol. Chem. 260, 9759-9774.

Rzhetsky, A., Nei, M., 1992. A simple method for estimating and testing minimum-evolution trees. Mol. Biol. Evol. 9, 945-967.

Saitoh, K., Hayashizaki, K., Yokoyama, Y., Asahida, T., Toyohara, H., Yamashita, Y., 2000. Complete nucleotide sequence of Japanese flounder
(Paralichthys olivaceus) mitochondrial genome: structural properties and cue for resolving teleostean relationships. J. Hered. 91, 271-278.

Seutin, G., Franz Lang, B., Mindell, D.P., Morais, R., 1994. Evolution of the WANCY region in amniote mitochondrial DNA. Mol. Biol. Evol. $11,329-340$

Strimmer, K., von Haeseler, A., 1996. Quartet puzzling: a quartet maximum-likelihood method for reconstructing tree topologies. Mol. Biol. Evol. 13, 964-969.

Sumida, M., Kanamori, Y., Kaneda, H., Kato, Y., Nishioka, M., Hasegawa, M., Yonekawa, H., 2001. Complete nucleotide sequence and gene rearrangement of the mitochondrial genome of the Japanese pond frog Rana nigromaculata. Genes Genet. Syst. 76, 311-325.

Swofford, D.L., 1998. PAUP*, Phylogenetic Analysis Using Parsimony (*and Other Methods), Version 4.0. Sinauer Associates, Sunderland.

Thompson, J.D., Higgins, D.G., Gibson, T.J., 1994. CLUSTAL W: improving the sensitivity of progressive multiple sequence alignment through sequence weighting, position specific gap penalties and weight matrix choice. Nucleic Acids Res. 22, 4673-4680.

Titus, T., Larson, A., 1995. A molecular phylogenetic perspective on the evolutionary radiation of the salamander family Salamandridae. Syst. Biol. 44, 125-151.

Trueb, L., Cloutier, R., 1991. A phylogenetic investigation of the interand intrarelationships of the Lissamphibia (Amphibia: Temnospondyli). In: Schultze, H.P., Trueb, L. (Eds.), Origins of the Major Groups of Tetrapods: Controversies and Consensus. Cornell Univ. Press, Ithaca, pp. $223-313$

Tzeng, C.S., Hui, C.F., Shen, S.C., Huang, P.C., 1992. The complete nucleotide sequence of the Crossostoma lacustre mitochondrial genome: conservation and variations among vertebrates. Nucleic Acids Res. 20, $4853-4858$.

Walberg, M.W., Clayton, D.A., 1981. Sequence and properties of the human KB cell and mouse L cell D-Loop regions of mitochondrial DNA. Nucleic Acids Res. 9, 5411-5421.

Wong, T.W., Clayton, D.A., 1985. In vitro replication of human mitochondrial DNA: accurate initiation at the origin of light-strand synthesis. Cell 42, 951-958.

Zardoya, R., Meyer, A., 1996. The complete nucleotide sequence of the mitochondrial genome of the lungfish (Protopterus dolloi) supports its phylogenetic position as a close relative of land vertebrates. Genetics $142,1249-1263$.

Zardoya, R., Meyer, A., 1997. The complete DNA sequence of the mitochondrial genome of a "living fossil", the coelacanth (Latimeria chalumnae). Genetics 146, 995-1010.

Zardoya, R., Meyer, A., 1998. Complete mitochondrial genome suggests diapsid affinities of turtles. Proc. Natl. Acad. Sci. U. S. A. 95, $14226-14231$.

Zardoya, R., Meyer, A., 2000. Mitochondrial evidence on the phylogenetic position of Caecilians (Amphibia: Gymnophiona). Genetics 155, $765-775$.

Zardoya, R., Meyer, A., 2001. On the origin of and phylogenetic relationships among living amphibians. Proc. Natl. Acad. Sci. U. S. A. 98, $7380-7383$.

Zardoya, R., Garrido-Pertierra, A., Bautista, J.M., 1995. The complete nucleotide sequence of the mitochondrial DNA genome of the rainbow trout, Oncorhynchus mykiss. J. Mol. Evol. 41, 942-951.

Zardoya, R., Cao, Y., Hasegawa, M., Meyer, A., 1998. Searching for the closest Living relative(s) of tetrapods through evolutionary analyses of mitochondrial and nuclear data. Mol. Biol. Evol. 15, 506-517. 